\title{
LÁ SE VÃO TRINTA ANOS DE ANPUR...
}

\section{HERE'S TO THE THIRTY YEARS OF ANPUR...}

\author{
ESTER LIMONAD \\ Universidade Federal Fluminense, Departamento de Geografia, Niterói, RJ, Brasil
}

Lá se vão mais de trinta anos desde a criação da ANPUR, e quase trinta e cinco anos desde que Ana Clara Torres Ribeiro (1944-2011) e eu nos conhecemos e ficamos amigas. Assim, aproveito este momento para, antes de falar da ANPUR, falar um pouco de Ana Clara Torres Ribeiro, uma das lutadoras por sua consolidação ${ }^{1}$, para depois tratar das propostas e das realizações dessa gestão (2011-2013) que se iniciou sob sua presidência. Faço isso movida por dois motivos, primeiro, por que não estaria aqui a fazer esse relato, se não fosse por insistência dela para que eu assumisse a secretaria executiva da ANPUR em sua gestão e, segundo, pelo fato de que após o seu precoce falecimento, em 9 de dezembro de 2011, não houve oportunidade para a sua diretoria registrar uma homenagem em sua memória.

Falar de Ana Clara Torres Ribeiro é uma tarefa árdua e dolorosa por nosso passado comum. Linhas e caminhos cruzados, no planejamento urbano e regional, nas ciências sociais e na geografia. Linhas que se esbarraram no Instituto de Pesquisa e Planejamento Urbano e Regional da Universidade Federal do Rio de Janeiro (IPPUR-UFRJ), então apenas programa de pós-graduação em planejamento urbano e regional, onde nos conhecemos, ficamos amigas e identificamos trajetórias, vivências e enfrentamentos similares, em campos de conhecimento alheios, que não os nossos. Não há palavras para expressar a falta que ela faz.

Fazer uma homenagem é sempre difícil, ainda mais se tratando de uma pessoa com uma enorme riqueza intelectual, complexidade e força de caráter como o foi Ana Clara Torres Ribeiro. Uma baixinha que ganhava ares de gigante quando se expressava e se colocava em público, que cativava coraçóes e mentes dos que a conheciam e daqueles que tampouco a conheciam. Que se apresentava simplesmente como socióloga e como professora do IPPUR-UFRJ, pois, como sempre dizia, essas coisas do Lattes ${ }^{2}$ são demasiado pomposas. Quem é? Quem foi essa mulher? Que falava com tanta leveza de coisas tão pesadas, que falava com tanta clareza de coisas tão complicadas, tâo complexas?

Ana Clara Torres Ribeiro foi uma pessoa de posiçôes explícitas, que se posicionava abertamente contra despotismos e intransigências, que sempre buscou defender a liberdade de expressão, a ação social e o enfrentamento às forças hegemônicas dominantes. Sua trajetória pessoal e acadêmica foi marcada por uma batalha incessante contra diferentes formas de autoritarismo, inclusive aquelas que se imiscuem de forma sutil em nosso cotidiano, em que alguns se assumem vigilantes dos outros. Combateu o pensamento único, as visôes particularizantes, totalizantes e generalizantes. Procurou sempre ler, de forma crítica e ágil, táticas e estratégias no cotidiano, em busca de respostas e de possibilidades de ação social.

1 Na ANPUR foi membro da Diretoria nas gestões de Milton Santos (1991-1993), de Heloisa Soares de Moura Costa (2003-2005) e de Leila Christina Dias (2009-2011) e Presidente Nacional de 27 de maio a 09 de dezembro de 2011.

2 Banco digital de curricula de pesquisadores do Conselho Nacional de Desenvolvimento Científico e Tecnológico (CNPq) (Disponível em: <http://lattes.cnpq.br>. Acesso em: 10 abr. 2017).

DOI: https://doi.org/10.22296/2317-1529.2017v19n2p219 
Ana Clara Torres Ribeiro deixou uma extensa obra esparsa, reunida e publicada em uma coleçãa ${ }^{3}$ organizada por amigos e companheiros de pesquisa. Uma obra que se insere e dialoga desde seu campo, a sociologia, com outros campos do conhecimento como a geografia, o planejamento e a arquitetura e urbanismo. Obra essa resultante de seu esforço em elaborar uma sociologia que busca entender o presente, que busca se colocar lado a lado com os fatos presentes e não ex-post aos fatos já havidos. Cabe lembrar que sua produção desde sempre foi atravessada pelo compromisso e pelo desafio de pensar socialmente o Brasil e pela preocupação do papel do fazer científico na compreensão das formas de dominação e, ao mesmo tempo, das formas e possibilidades de resistências e insurgências.

Seu último trabalho, seu memorial do concurso de titular, publicado como homenagem dessa diretoria pela ANPUR e pela editora Letra Capital (RIBEIRO, 2012), propôe uma cartografia da ação social no âmbito de uma sociologia do presente, no intuito de instrumentalizar formas de luta e resistência contra os processos hegemônicos de dominação. Em sua construção inter-relaciona três ideias, conceitos fundantes, recuperando assim seu trabalho e diálogo com Milton Santos, velho amigo seu, presidente da ANPUR entre 1991-1993. Propóe, assim, uma sociologia do presente com base na Ação, Técnica e Espaço, contextualizada na reflexão da radicalização da democracia, contra a criminalização da pobreza e de compreensão da profunda crise societária que perpassa a contemporaneidade. Com um olhar no futuro, Ana Clara Torres Ribeiro elegeu a ação social, as práticas de inclusão dos jovens como foco central de sua reflexão e ação a partir de uma perspectiva interdisciplinar em suas cartografias da ação social.

Com este norte e com a esperança de alcançar outros patamares de ação e de intervenção, Ana Clara Torres Ribeiro coordenou a comissão organizadora do XIII Encontro Nacional da ANPUR com o tema "Quem planeja o território?"’ , que foi aberto à participação de representantes dos movimentos sociais e de estudantes de graduação. Este encontro reuniu, de forma inédita, mais de 2.500 inscritos em dez sessôes temáticas e cinquenta e oito sessões livres. Na assembleia geral desse XIV Encontro Nacional, o IPPUR-UFRJ apresentou a candidatura de Ana Clara Torres Ribeiro à frente de uma diretoria ${ }^{5}$ reunida em torno de suas ideias e propostas.

O falecimento precoce e inesperado de Ana Clara Torres Ribeiro legou à essa diretoria diversas consignas e gerou uma situação inusitada no âmbito da ANPUR. Pois, em obediência a seu Estatuto (ANPUR, 2009), cabia ao secretário-executivo assumir e acumular a presidência da associação até o prazo estatutário limite para a realização da assembleia anual. Por conseguinte foi convocada, dentro do prazo e dos parâmetros legais, uma assembleia geral para o dia 2 de abril de 2012. Nessa assembleia realizada no auditório do IPPUR-UFRJ, candidatamo-nos e fomos eleitos, eu no cargo de presidente da ANPUR, Benny Schvarsberg (FAU-UnB) no cargo de Secretário-Executivo e Orlando Alves dos Santos Júnior (IPPUR-UFRJ) no cargo de Secretário-Adjunto para dar consecução ao mandato da gestão 2011-2013 (ANPUR, 2012a), em conjunto com os demais membros da diretoria eleita em 27 de maio de 2011.

Ao fim de nossa gestão completavam-se vinte e sete anos desde o I Encontro Nacional, realizado em

3 Coleção de 5 volumes organizada por uma comissão com o suporte direto da família de Ana Clara Torres Ribeiro e publicada pela editora Letra Capital (RIBEIRO, 2013).

4 O XIV ENANPUR foi realizado no Rio de Janeiro de 22 a 27 de maio de 2011. Os Anais do Encontro encontram-se disponibilizados em: <http://www.anpur.org.br/anais/>. Acesso em: 10 abr. 2017.

5 Diretoria executiva composta por mim, Ester Limonad (Programa de Pós-graduação em Geografia da Universidade Federal Fluminense) no cargo de secretaria-executiva e Benny Schvarsberg (Programa de Pós-Graduação em Arquitetura e Urbanismo da Universidade de Brasília) no cargo de secretário-adjunto, Lilian Fessler Vaz (Programa de Pós-Graduação em Urbanismo da Universidade Federal do Rio de Janeiro), Maria Ângela de Almeida Souza (Programa de Pós-Graduação em Desenvolvimento Urbano da Universidade Federal de Pernambuco), María Mónica Arroyo (Programa de Pós-graduação em Geografia Humana da Universidade de São Paulo) e Paola Berenstein Jacques (Programa de Pós-Graduação em Arquitetura e Urbanismo da Universidade Federal da Bahia) na diretoria; a que se somou um conselho fiscal composto por Angelo Szaniecki Perret Serpa (Programa de Pós-graduação em Geografia da Universidade Federal da Bahia), Cibele Saliba Rizek (Programa de Pós-Graduação em Arquitetura e Urbanismo da Universidade de São Paulo, campus São Carlos), Elson Manoel Pereira (Programa de Pósgraduação em Geografia da Universidade Federal de Santa Catarina), Paulo Pereira de Gusmão (Programa de Pós-graduação em Geografia da Universidade Federal do Rio de Janeiro) e Saint-Clair Cordeiro da Trindade Júnior (Núcleo de Altos Estudos Amazônicos da Universidade Federal do Pará). 
Nova Friburgo, estado do Rio de Janeiro, quando foi apresentado o Balanço Técnico-Científico em Planejamento Urbano, Regional e Tecnologia Habitacional (RANDOLPH; LIMONAD, 1986). Ocasião em que Ana Clara Torres Ribeiro e eu coordenamos uma das sessóes temáticas relativas ao Planejamento Urbano (ANPUR, 1986). Sem dúvida percorremos um longo trajeto, desde a fundação da ANPUR, em 1983, por ocasiáo de uma reuniáo realizada na sala da diretoria da Faculdade de Arquitetura e Urbanismo da Universidade de São Paulo com a presença de cinco programas de pós-graduação ${ }^{6}$.

Cabe recordar que esses programas de planejamento urbano e regional se constituíram, entre 19711972, no âmbito de um convênio, com duração prevista de sete anos, realizado entre a Coordenação de Aperfeiçoamento de Pessoal de Ensino Superior (CAPES), órgão do Ministério da Educação, e o Ministério do Interior com suporte e financiamento direto desse ministério. Convênio esse realizado em decorrência de uma intenção expressa de formar quadros para órgãos de governo, com base nas metas do II Plano Nacional de Desenvolvimento, elaborado durante o governo do presidente general Emilio Garrastazu Médici (1969-1973), um dos mais duros governos da ditadura militar.

A fundação e construção da ANPUR deu-se, assim, durante a transição da ditadura militar para o regime democrático. E, de certa forma, o fortalecimento e inserção político-institucional da associação em diversas esferas estaria relacionada a muitas das transformaçôes político-institucionais havidas no Brasil no decorrer dos últimos trinta anos.

A ANPUR desde sua fundação encontra-se em constante renovação e, em parte isto se deve, por um lado, à perspectiva crítica que a orienta, e por outro à interdisciplinaridade, que a caracteriza e permite que seja um fórum de diferentes áreas do conhecimento, que se encontram e debruçam sobre temas comuns, contribuindo para o diálogo interdisciplinar e para o enriquecimento conceitual. O fato é que a ANPUR congrega membros de outras associaçôes nacionais de pós-graduação e pesquisa, entre elas a Associação Nacional de Pesquisa e Pós-Graduação em Administração (ANPAD), a Associação Nacional de Pesquisa e Pós-Graduação em Arquitetura e Urbanismo (ANPARQ), a Associação Nacional dos Centros de Pós-Graduação em Economia (ANPEC), a Associação Nacional de Pós-Graduação e Pesquisa em Geografia (ANPEGE), a Associação Nacional de Pós-Graduação e Pesquisa em Ciências Sociais (ANPOCS), a Associação Nacional de História (ANPUH) e quase todos membros institucionais da Associação Brasileira de Estudos Populacionais (ABEP). Cabe ressaltar que o corpo técnico de diversos órgãos de governo costuma participar de seus encontros nacionais e seminários temáticos, uma vez que os membros da ANPUR têm contribuído para a formação de quadros técnico-administrativos de governo e participado incisivamente dos conselhos da cidade, fórum da reforma urbana e outros na perspectiva de construção da nação.

\section{DIAGNÓSTICO E PLATAFORMA DE AÇÃo}

Por ocasião da eleição da diretoria para o período 2011-2013, em 27 de maio de 2011, pudemos observar a permanência e transformação de temas relacionados ao ensino de planejamento urbano e regional, às mudanças na interação da interface planejamento-urbanismo, assim como a crescente complexificação e diversificação das questóes urbanas, regionais e ambientais. Temas esses que deixaram de estar compartimentados em campos disciplinares específicos, que se mesclaram e passaram a incorporar outras dimensôes e outras escalas, com a diversificação e ampliação das questôes urbano-regionais. Essa

6 A saber, quatro programas na área de planejamento urbano e regional (Programa de Pós-Graduação em Planejamento Urbano e Regional da Universidade Federal do Rio de Janeiro, Mestrado em Desenvolvimento Urbano da Universidade Federal de Pernambuco, Programa de Pós-Graduação em Planejamento Urbano e Regional da Universidade Federal do Rio Grande do Sul e o Programa de Pós-Graduação em Planejamento e Desenho Urbano da Universidade de Brasília) e o Programa de Pós-Graduação em Arquitetura e Urbanismo da Universidade de São Paulo. 
complexificação e diversificação evidenciavam-se na crescente preocupação com problemas urbano-ambientais e questôes urbano-regionais, às quais se somam a dimensão cultural, os movimentos sociais no campo e na cidade, bem como através da incorporação da temática do desenvolvimento rural, da integração latino-americana e, mais recentemente, de questôes relacionadas ao agronegócio, às fronteiras internacionais e ao desenvolvimento macrorregional. Notava-se, então, também, um aumento da preocupação com as identidades culturais e as territorialidades, que apenas se esboçava nas sessôes livres, criadas por ocasião do V Encontro Nacional da ANPUR, realizado em Belo Horizonte, em 1993. Cabe destacar que diversos temas das sessôes livres atravessam a história da ANPUR e outros se transmutam, conforme as pesquisas e preocupações dos pesquisadores e docentes, que os alimentam, se aprofundam ou incorporam novas questóes.

Havia, ainda, que considerar as mudanças havidas na área de pós-graduação e de pesquisa em Planejamento Urbano e Regional na CAPES e no CNPq. Uma vez que, entre meados da década de 1990 e 2010, verifica-se a constituição e consolidação de ao menos 17 (dezessete) programas de desenvolvimento regional e/ou planejamento territorial e ambiental em diversas unidades da federação, muitos dos quais não se encontravam filiados à ANPUR, em virtude de uma recomendação feita na assembleia geral de 1989 de se aguardar um interstício de três anos a partir da criação dos programas candidatos à filiação, uma vez que até então não havia um processo de aprovação de novos programas e de avaliação sistemática por parte da CAPES. Muitos destes programas foram criados, principalmente, em áreas interiorizadas ou de fronteira, fora das regiōes metropolitanas, com um quadro de preocupaçôes distinto dos programas originários e dos até então filiados e associados à ANPUR. As preocupaçôes desses programas se inseriam em temáticas levantadas em diferentes períodos da história da ANPUR e resgatavam a questão regional sob diferentes aspectos e temáticas (RANDOLPH, 2013; ROVATI, 2013). Já no CNPq observava-se um aumento da demanda por fomento vis a vis a um modesto aumento do volume de bolsas de pesquisa e de fomento para a área (FERNANDES, 2013).

Enfim, o diagnóstico inicial apontava para uma certa fragilidade institucional da associação, em particular no que se referia à transição de diretorias entre uma gestão e outra, à uma compartimentação dos associados ao redor de interesses específicos e localizados, bem como um certo descolamento entre a associação, seus membros e o seu veículo institucional maior - a Revista Brasileira de Estudos Urbanos e Regionais. Além disso, era perceptível uma maior ênfase em alguns temas em detrimento de outros. Para dar conta destas questóes, durante os primeiros meses da gestão de Ana Clara Torres Ribeiro, entre maio e setembro de 2011, foi elaborada em reuniôes da diretoria uma plataforma de ação, a qual tinha por norte geral:

- dar continuidade e aprofundar a concepção e o caráter da ANPUR como entidade acadêmica agregadora e articuladora de um conjunto de programas e de instituiçôes de pós-graduação e de pesquisa de natureza multi e pluridisciplinar, respeitando as especificidades das diversas disciplinas que a compóem, no processo permanente de construção de uma política de pesquisa, ensino e produção do conhecimento na área de planejamento urbano e regional. Isso demandava fortalecer a associação e a área de pesquisa e ensino de planejamento urbano e regional, bem como alcançar uma maior organicidade entre a associação, seus membros, seus veículos de difusão e suas formas de representação, a saber a Revista Brasileira de Estudos Urbanos e Regionais e os distintos seminários itinerantes temáticos da associação, como os seminários de: História da Cidade e do Urbanismo; de Ensino, Pesquisa e Extensão em Planejamento Urbano e Regional; e o de Áreas de Preservação Permanente Urbanas.

- reforçar a perspectiva da ANPUR, enquanto uma entidade acadêmica nacional que se insere de modo autônomo, crítico e independente, do ponto de vista político e ideológico, junto às entidades e aos movimentos sociais nas lutas e causas democráticas, populares e emancipatórias, assim como na construção de políticas públicas e de Estado socialmente justas e inclusivas, com métodos 
democráticos e processos participativos. O reforço dessa perspectiva tinha por meta dar sequência à trajetória histórica da ANPUR de solidariedade e participação no Fórum Nacional da Reforma Urbana, juntamente com entidades técnicas, profissionais, movimentos sociais e culturais, de modo a contribuir com a construção e implementação de uma Politica de Reforma Urbana no Brasil.

Tratava-se, portanto, de implementar esta plataforma através de três eixos de ação articulados, detalhados adiante, voltados para

1) o fortalecimento institucional;

2) o aprofundamento das relaçóes institucionais e aumento da projeção externa da associação; e

3) a veiculaçấo e incremento da divulgação da produçáo acadêmica.

\section{FORTALECIMENTO INSTITUCIONAL}

A proposta de fortalecimento institucional concernia duas esferas de ação: uma interna e uma interinstitucional. A esfera de açáo em termos internos compreendia:

- a perspectiva de ampliação do quadro de filiados com a mudança da sistemática de filiação, de modo a acolher os programas de pós-graduação de desenvolvimento regional e os mestrados profissionais da área de planejamento urbano e regional criados a partir de 2001;

- buscar um aumento da organicidade interna da associação e de seus membros através da abertura de canais de participação e de representação, bem como através do diálogo com base em questốes comuns e concretas;

- uma reestruturação interna da associação, o que demandava proceder a mudanças estatutárias e a elaboração de um regimento geral da associação e uma revisão de seu estatuto com a meta:

- de definir cargos e atribuiçóes para os membros da diretoria;

- normatizar e regular a transição de diretorias com um interstício de dois a três meses entre uma diretoria e outra, de modo a viabilizar a oficializaçáo legal da nova diretoria;

- deslocar o evento nacional para o recesso de meio de ano de modo a poder utilizar as instalaçôes universitárias.

\section{RELAÇões INSTITUCIONAIS}

Em termos do aprofundamento das relaçôes interinstitucionais e da projeção externa da ANPUR a plataforma de açáo abrangia as relaçôes da ANPUR em esfera nacional e internacional, nos âmbitos acadêmico e político, a saber:

- $\quad$ Na escala nacional tratava-se de:

- promover o fortalecimento acadêmico da Área de Planejamento Urbano e Regional através da ampliaçáo de sua presença junto aos órgáos oficiais federais, estaduais e municipais, de ensino superior, pesquisa e fomento (CAPES; CNPq; Financiadora de Estudos e Projetos (FINEP); Instituto de Pesquisa Econômica Aplicada (IPEA); e Fundaçóes Estaduais de Amparo à Pesquisa (FAPs)). No intuito de ampliar e incrementar os investimentos em pesquisa da subárea de Planejamento Urbano e Regional na grande área de Ciências Sociais Aplicadas, e desta em relação às demais no sistema nacional de Ciência e Tecnologia, especialmente no CNPq e na CAPES;

- Manter e aprofundar a relação da ANPUR com associações acadêmicas afins, como Sociedade Brasileira para o Progresso da Ciência (SBPC); Associação Brasileira de Antropologia (ABA); ABEP; Associação dos Geógrafos Brasileiros (AGB); ANPAD; ANPARQ; ANPEGE; ANPOCS; e Sociedade Brasileira de Sociologia (SBS), reforçando mutuamente os encontros 
nacionais dessas associações e entidades, buscando ampliar o conjunto de interlocutores disciplinares e criar alianças de modo a fortalecer as reivindicações das áreas de Ciências Sociais Aplicadas e de Ciências Humanas junto aos órgãos de fomento;

- Ampliar a interlocução com associaçôes profissionais afins (Conselho de Arquitetura e Urbanismo do Brasil (CAU); Conselho Regional de Engenharia e Agronomia (CREA); SBS; Centro Celso Furtado; etc.) e com órgãos de governo (Ministério das Cidades; Ministério da Integração; etc.) no sentido de viabilizar acompanhamentos, avaliaçôes críticas e posicionamentos qualificados sobre planos, políticas e programas de caráter urbano e regional.

- Em escala internacional, a intenção era:

- manter, fortalecer e ampliar a relação e os compromissos construídos com entidades congêneres internacionais no campo do planejamento urbano e regional à exemplo do Global Planning Education Association Network (GPEAN), da Red Iberoamericana de Investigadores Sobre Globalización y Territorio, do Consejo Latinoamericano de Ciencias Sociales (CLACSO) e da Association pour la Promotion de l'Enseignement et de la Recherche en Aménagement et Urbanisme (APERAU), entre outros, no sentido de aumentar o intercâmbio acadêmico e científico e a troca de experiências de ensino e pesquisa em planejamento urbano e regional;

- promover eventos de cunho internacional com a participação das entidades congêneres de modo a ampliar o intercâmbio acadêmico e a visibilidade da associação.

\section{PROdUÇÃo ACADÊMICA E VISIBILIDAdE}

A divulgação e incremento da difusão da produção acadêmica dos filiados e associados e das posiçôes da associação estariam assentadas na perspectiva de:

- promover o fortalecimento da Revista Brasileira de Estudos Urbanos e Regionais enquanto veículo institucional da associação e aumentar sua interaçáo com os membros da associação. Isso demandava, entre outras medidas, açôes para viabilizar a indexaçâo, a obtenção de financiamentos e a atualização da revista;

- difundir e divulgar a produção acadêmico-científica dos membros e do acervo da associação;

- criar uma política editorial e promover seminários temáticos, além dos existentes, para ampliar a visibilidade da associação e de seus membros.

\section{REALIZAÇÕES}

Entre maio de 2011 e 31 de julho de 2013, em consonância com o diagnóstico e proposições da plataforma de ação, foram realizadas algumas mudanças de cunho institucional. Muitas inspiradas, em parte, em propostas e ideias enraizadas de Ana Clara Torres Ribeiro, as quais compartilhávamos. Várias dessas propostas foram realizadas considerando-se as mudanças havidas na área de Planejamento Urbano e Regional conforme abordaremos a seguir, seguindo os tópicos da plataforma de ação.

\section{FORTALECIMENTO INSTITUCIONAL}

\section{AMPLIAÇÃO DO QUADRO DE FILIADOS E ASSOCIADOS}

Durante a gestão logrou-se uma maior integração dos programas de desenvolvimento regional criados 
a partir de 2001. Isso contribuiu para ampliar o raio de ação da associação nos programas de pós-graduação da área e de áreas afins. Para que isso ocorresse, alterou-se a sistemática de filiação, ao se deixar de exigir aos programas candidatos a apresentação de "um relato das atividades de ensino e pesquisa desenvolvidas pela entidade (Programa, etc.) nos últimos cinco anos [...]” (ANPUR, 1989). Posto que, uma pesquisa das atas da associação revelou que esta prática devia-se a uma sugestáo ${ }^{7}$, feita em 1989, com a ressalva desta não constar no estatuto da Associação. Sugestão oportuna naquela ocasiáo, mas que se tornou obsoleta em razão das atuais exigências da CAPES para a criação de novos programas. Abriu-se, assim, a possibilidade de filiação de programas novos e recém-criados, desde que observadas as normas estatutárias.

Assim, entre 27 de maio de 2011 e 24 de maio de 2013, após uma incisiva campanha para a ampliação do quadro institucional, feita junto aos programas de pós-graduação da área de planejamento urbano e regional, com o apoio da respectiva comissão de área da CAPES, doze programas de pós-graduaçãoo ${ }^{8}$ tornaram-se membros da ANPUR, dos quais nove pertencem á área de planejamento urbano e regional na CAPES.

Em consequência, alterou-se a participação e distribuição das áreas de conhecimento no âmbito da ANPUR, conferindo à área de Planejamento Urbano e Regional um maior peso e preeminência, com uma ênfase renovada no planejamento e desenvolvimento regional. Paralelamente, ampliou-se a distribuição geográfica dos programas filiados com um significativo aumento da participação dos programas das regióes Norte, Nordeste e Sul do país.

Soma-se a esta ampliação do quadro de membros, os esforços envidados, em especial, para retomar o contato com os membros que se encontravam afastados da associação. Nesse sentido diversos programas manifestaram o desejo de se manter na associação, prontificando-se a atualizar suas pendências, enquanto que quatro programas ${ }^{9}$ deixaram, por opção própria, de fazer parte do quadro de membros da Associação.

\section{MUDANÇAS INSTITUCIONAIS}

Nos últimos anos a ANPUR experimentou muitas mudanças e transformações, cresceu e diversificou seu espectro de preocupaçôes e atividades. A consolidação, maturidade e complexificação da ANPUR demandaram algumas mudanças de cunho institucional. Nesse sentido foram aprovadas mudanças no Estatuto da associação em relação à divisão de tarefas entre o secretário executivo e o secretário-adjunto. Embora tenha sido sugerido à assembleia geral extraordinária de 08.11.2012 a criação de atribuiçóes para os membros da diretoria (publicaçôes, eventos, fomento, relaçóes internacionais), estes permaneceram sem atribuiçóes específicas. Logrou-se, todavia, alcançar um avanço em relação a transmissão de cargos e ao período de transição entre diretorias com a aprovação estatutária

7 Sugestão feita pelo Prof. Carlos Bernardo Vainer (IPPUR-UFRJ), aprovada na assembleia geral ordinária realizada em 1989, em Águas de São Pedro (SP) (ANPUR, 1989).

8 Esses programas tornaram-se membros da ANPUR no decurso da Assembleia Geral Ordinária de 08.11.2012 (ANPUR, 2012c) e da Assembleia Geral Ordinária de 24.05.2013 (ANPUR, 2013), conforme segue: Programa de Pós-Graduação em Planejamento Territorial e Desenvolvimento Socioambiental da Universidade do Estado de Santa Catarina (UDESC), Mestrado em Políticas Sociais e Dinâmicas Regionais da Universidade de Chapecó (UNOCHAPECÓ), Programa de Pós-Graduação em Desenvolvimento Econômico da Universidade Estadual de Campinas (UNICAMP), Programa de Pós-Graduação em Estudos Urbanos e Regionais da Universidade Federal do Rio Grande do Norte (UFRN) e Programa de Pós-Graduação em Desenvolvimento Territorial e Políticas Públicas da Universidade Federal Rural do Rio de Janeiro (UFRRJ) (ANPUR, 2012c); e Programa de Pós-Graduação em Desenvolvimento Regional da Universidade Federal do Amapá (UNIFAP), Programa de Pós-Graduação em Desenvolvimento Regional da Universidade Federal de Tocantins (UFT), Programa de Pós-Graduação em Desenvolvimento Regional da Universidade Tecnológica Federal do Paraná (UTFPR), Programa de Pós-Graduação em Arquitetura e Urbanismo da Universidade Federal da Pará (UFPA), Programa de Pós-Graduação em Desenvolvimento Regional da Universidade Estadual da Paraíba (UEPB), Programa de Pós-Graduação em Planejamento e Gestão do Território da Universidade Federal do ABC e Programa de Pós-Graduação em Geografia da Universidade Federal de Pernambuco (ANPUR, 2013).

9 A Pós-Graduação em Engenharia de Construção Civil e Urbana da Universidade de São Paulo (USP); o Programa de Pós-Graduação em Sociologia da Universidade de Brasília (UnB); a Fundação Instituto de Pesquisas Econômicas (FIPE); e o Núcleo de Estudos Urbanos e Regionais da Universidade Estadual de Campinas (Unicamp) (ANPUR, 2012c). 
de um interstício de dois meses entre a eleição da nova gestão e a posse da nova diretoria. Em razão dessa modificação, essa gestão foi prorrogada até 31 de julho de 2013 (ANPUR, 2012b).

Foi, também, proposto por esta diretoria e aprovado em assembleia o Prêmio Ana Clara Torres Ribeiro de livros em Planejamento Urbano e Regional (ANPUR, 2012c). Além disso, foram aprovadas diversas alteraçôes no Prêmio ANPUR, graças a uma proposta de regulamento elaborada por Cibele Saliba Rizek e María Mónica Arroyo, com destaque para o processo de submissão de teses e dissertaçóes, que passou a ser feito institucionalmente através do encaminhamento pelos coordenadores dos programas de pós-graduação, devendo os trabalhos indicados ser acompanhados por um parecer qualificado de uma comissão ad hoc de cada Programa de Pós-Graduação e da ata de defesa.

\section{AUMENTO DA ORGANICIDADE DA ANPUR}

Foram envidados esforços de aproximação com os diversos programas, em particular com aqueles que se encontravam em processo de distanciamento. Logrou-se uma reaproximação com os programas da área de administração (UFBA e FGV-SP) e de economia (UNICAMP), entre outros. Esses esforços resultaram na inserção de representantes desses programas no Conselho Editorial da Revista Brasileira de Estudos Urbanos e Regionais e/ou nos júris de teses e de dissertaçôes da premiação da ANPUR em 2013.

Buscou-se dar um efetivo suporte institucional e/ou um aporte inicial de recursos à realização dos seminários temáticos da ANPUR, que o solicitaram ${ }^{10}$. O VI Seminário de Avaliação de Ensino e Pesquisa em Estudos Urbanos e Regionais com o tema "Encruzilhadas do Ensino, Pesquisa e Extensão do Planejamento Urbano e Regional”, organizado por Benny Schvarsberg (secretário-executivo dessa diretoria), contou com a participação de convidados nacionais e internacionais com destaque para Clélio Campolina Diniz, reitor da UFMG, e Sandra Braga, do CNPq, que falaram sobre as perspectivas de pesquisa e as possibilidades de fomento para a área. Além deles Andrea I. Frank, vice-presidente do GPEAN e docente da Universidade de Cardiff, e Sílvia Gorenstein, vice-coordenadora da RIII e docente da Universidad del Litoral, que fizeram um aporte sobre as experiências de ensino e de pesquisa na Europa e na América Latina.

Além desse seminário, apoiou-se direta e indiretamente, também, a realização de diversos eventos ${ }^{11}$ e a realização de acordos de fomento ${ }^{12}$ e de cooperação, que permitiram aprofundar a interlocução entre a diretoria e os membros da associação. Cabe ressaltar que todos esses eventos contaram com recursos e suporte direto e indireto dos órgãos de fomento (CAPES, CNPq, IPEA e FAPs, bem como das Pró-Reitorias das instituições organizadoras).

\section{RELAÇÕES INSTITUCIONAIS}

De modo a dar consecução às metas da proposta dessa gestáo implementou-se uma série de açóes com vistas a aprofundar as relaçôes interinstitucionais e aumentar a projeçâo externa. Nesse sentido, na escala nacional estreitou-se, em particular, as interações da associação com o IPEA, o Banco Nacional do Desenvolvimento Econômico e Social (BNDES), o Ministério da Integração Nacional, Ministério

\footnotetext{
10 Nesse sentido foram realizados convênios de fomento com as Fundações Universitárias e com órgãos de fomento (CAPES, CNPq, IPEA), para a realização do II Seminário de Áreas de Preservação Permanente Urbana, em Natal - RN, organizado por Dulce Maria Bentes Sobrinha (PPGAU-UFRN); do I Seminário de Desenvolvimento Regional Estado e Sociedade, no Rio de Janeiro - RJ, organizado por Rainer Randolph (IPPUR-UFRJ); e do VI Seminário de Ensino e Pesquisa em Estudos Urbanos e Regionais, organizado por Benny Schvarsberg (PPG/FAU-UnB). 11 Destacam-se, entre outros, a realização dos seminários temáticos da ANPUR: I Seminário de Desenvolvimento Regional Estado e Sociedade, II Seminário de Áreas de Preservação Permanente Urbanas, XI Seminário de História da Cidade e do Urbanismo, VI Seminário de Avaliação do Ensino e Pesquisa em Estudos Urbanos e Regionais. Aos quais se somam a participação em outros eventos nacionais e internacionais promovidos pelos membros da ANPUR.

12 Deu-se consecução ao programa de bolsas de mestrado ANPUR-IPEA sob a coordenação de Geraldo Magela Costa (Instituto de Geociências da Universidade Federal de Minas Gerais).
} 
das Cidades, assim como com outras associaçóes nacionais, com destaque para a ANPOCS, ABEP, ANPAD, ANPEGE, ANPARQ e SBPC.

No concernente ao CNPq foi feito um levantamento junto aos membros da ANPUR para a indicação de três nomes, que resultou na indicação exitosa de Norma Lacerda (2012-2015) para a representação de área. Foram feitas gestôes, também, para a indicação de um suplente para essa representação, apontando-se nesse sentido a necessidade de delineação de uma política científica e de pesquisa para a área de planejamento urbano e regional.

A interação da ANPUR com o IPEA merece uma menção especial. Durante a gestão de Marcio Pochmann, o IPEA deu um suporte substancial à área de ciências humanas e sociais aplicadas, ao abrir um fórum de interlocução entre diversas associações nacionais de pesquisa e pós-graduação. As ações do IPEA facultaram que entrássemos em contato direto com a ANPOCS, SBS e ABA, entre outras associaçôes nacionais de pesquisa e pós-graduação. Além disso, essa interação ANPUR-IPEA permitiu dar continuidade ao convênio de bolsas de mestrado, sob a coordenação de Geraldo Magela Costa (IGC -UFMG) e foi aberto um edital de fomento a periódicos das áreas de ciências sociais e sociais aplicadas, que contemplou a Revista Brasileira de Estudos Urbanos e Regionais durante o ano de 2012. Ainda sob a gestão de Ana Clara Torres Ribeiro, a ANPUR participou ativamente da organização e da realização da II Conferência Nacional do Desenvolvimento (CODE), realizada em Brasília, com uma mesa redonda sobre o tema "Desenvolvimento e Espaço: Açôes, Escalas e Recursos"13, havendo sido organizado um simpósio com o tema "Desenvolvimento e Espaço" que contou com a apresentação de quase cem trabalhos selecionados por uma comissão mista composta por técnicos do IPEA e docentes e pesquisadores dos membros da ANPUR.

Durante nossa gestão, também se aprofundou a interação com o Centro Internacional Celso Furtado de Políticas para o Desenvolvimento, do qual Ana Clara Torres Ribeiro era membro. Isso resultou na participaçáo da ANPUR no júri de premiação de teses deste centro, representada por Alexandre Mendes da Cunha (CEDEPLAR-UFMG); em nossa participação no II Seminário Nacional da Rede Brasileira de Cidades Médias e em nossa participação no lançamento do Observatório Celso Furtado para o Desenvolvimento Regional, bem como na I Conferência Nacional do Desenvolvimento realizada em Brasília.

No âmbito acadêmico a ANPUR marcou presença no 36 Encontro Anual da ANPOCS com a realização de uma mesa-redonda sobre "Dilemas e desafios do planejamento na resolução dos problemas e redução das desigualdades sociais" ${ }^{\prime \prime}$, bem como no XVIII Encontro Nacional da ABEP e no XII Colóquio Internacional de Poder Local com o tema "Metamorfoses do Poder Local e Itinerários do Desenvolvimento Territorial”, organizado pelo Centro Interdisciplinar de Desenvolvimento e Gestão Social (CIAGS) da UFBA, em que participamos da mesa de abertura desses eventos, bem como de outras atividades.

A ANPUR participou, ainda, da reunião organizada pela SBPC com representantes das diversas ANPs com o Ministro da Ciência e Tecnologia, Marco Antônio Raupp, e o Presidente do CNPq, Glaucius Oliva, onde juntamente com os representantes da ABA e da ANPOCS postulou a necessidade de criação de uma Diretoria de Ciências Humanas e Sociais Aplicadas no CNPq. Ainda no âmbito da SBPC foi proposta e aprovada a realização de um Simpósio com o tema "Um novo Planejamento para um novo Brasil?" realizado no âmbito da 65a Reuniāo Anual da SBPC, que teve por tema "Ciência para o Novo Brasil”. Este simpósio contou com a participação de membros das diversas áreas do conhecimento da ANPUR reunidos em seis mesas redondas, e que resultou na edição de um livro com o mesmo

13 Essa mesa redonda contou com a participação de Aldo Paviani (Programa de Pós-Graduação em Geografia da Universidade de Brasília); Flávio Villaça (Programa de Pós-Graduação em Arquitetura e Urbanismo da Universidade de São Paulo); Ester Limonad (secretária executiva da ANPUR); Rodrigo Ferreira Simões e Roberto Luís de Melo Monte-Mór (Centro de Desenvolvimento e Planejamento Regional da Universidade Federal de Minas Gerais).

14 Que contou com a participação de Carlos Bernardo Vainer (UFRJ), Edna Ramos Castro (UFPA) e Ester Limonad (UFF). 
título desse simpósio (LIMONAD; CASTRO, 2014).

Com a intenção de imprimir e estender a presença política da ANPUR, como um interlocutor qualificado, no debate e formulação, bem como no acompanhamento e avaliação crítica da implementação das Políticas Nacionais de Desenvolvimento Urbano e Regional, bem como nas políticas públicas afins e setoriais (transportes, saneamento, habitação, ciência e tecnologia, educação, etc.), a ANPUR participou efetivamente do Conselho Gestor do Fundo Nacional de Habitação de Interesse Social (FNHIS), do Conselho das Cidades e da Comissão Executiva Nacional do Plano Nacional de Desenvolvimento Regional ${ }^{15}$. A forma de participação e os desdobramentos dessa participação, em face da dinâmica, da composição, do modelo e efetividade dessas instâncias, levaram-nos a questionar a validade da inserção da associação nesses canais institucionais. Exceção seja feita nesse sentido à participação no Conselho das Cidades, que ficou a cargo de Orlando Alves dos Santos Júnior (IPPUR-UFRJ).

No âmbito internacional a ANPUR buscou consolidar e aprofundar os compromissos com o GPEAN e com a RII. No encontro bianual da RII, realizado em Belo Horizonte, esta gestão se fez representar nos grupos de trabalho por Adauto Lucio Cardoso (IPPUR-UFRJ) e participou na realização de uma mesa redonda em homenagem a Ana Clara Torres Ribeiro. Com relação ao GPEAN a ANPUR participou da reunião anual realizada em Lausanne ${ }^{16}$, Suíça, e das reuniōes havidas no âmbito do XV ENANPUR, realizado em Recife, e do encontro da AESOP-ACSP ${ }^{17}$, realizado em Dublin. Em Recife, durante a reunião anual do GPEAN, foi apresentada e aprovada a proposta do IPPUR-UFRJ de organizar o IV WPSC (Word Planning Schools Conference) no Rio de Janeiro, em julho de 2016. Em Dublin foram discutidas a possibilidade de os encontros do WPSC substituírem os encontros da AESOP-ACSP e a viabilidade de haver uma maior interação editorial entre os membros do GPEAN, que vá além da publicação do Dialogues in Urban and Regional Planning (DURP), nos quais a ANPUR se faz representar por Heloisa Soares de Moura Costa (IGC-UFMG).

\section{Produção ACAdÊMICA E VISIBILIDAdE}

Em termos práticos o fortalecimento da Revista Brasileira de Estudos Urbanos e Regionais, enquanto veículo institucional da associação, bem como de comunicação e difusão da produção acadêmico-científica no campo do planejamento e estudos urbanos e regionais demandava uma série de açôes para torná-la passível de indexação e inserção na base da Scientific Eletronic Library Online (SciELO), de modo a cumprir com as exigências dos órgãos de financiamento.

Entre essas açôes era urgente a disponibilização da revista em uma base de dados digital de fácil acesso. Optou-se nesse sentido, ainda durante o interstício de Ana Clara Torres Ribeiro, implantar a revista na base de software aberto Open Jornal System (OJS). Essa disponibilização foi alcançada em outubro de 2011 e disponibilizada em dezembro de 2011. Isso só se fez possível graças ao trabalho diligente de digitalização dos anais pelas gestôes precedentes de Edna Castro (2007-2009) e Leila Christina Duarte Dias (2009-2011). A disponibilização da revista no formato OJS, com sistema indexado de busca por autores e palavras-chave, contribuiu para ampliar a difusão da revista e aumentar de forma significativa a visibilidade da ANPUR ao nível mundial. Alcançamos em julho de 2013 de 50 a 100 novos acessos por dia, das mais diversas partes do mundo, e que vai ao encontro das exigências da SciELO e da Red de Revistas Cientificas de America Latina y el Caribe, España y Portugal (Redalyc).

Cabe mencionar, ainda, que a disponibilização digital gratuita da revista juntamente com a passagem dos encargos de produção e distribuição para a editora Letra Capital levaram a algumas mudanças

15 Nos quais a ANPUR se fez representar por Benny Schvarsberg e Maria Ângela de Almeida Souza (FNHIS), por Orlando Alves dos Santos Júnior (Conselho das Cidades), por Ester Limonad e Rodrigo Simões (Comissão Executiva Nacional do Plano Nacional de Desenvolvimento Regional). 16 Onde se fez representar por Ester Limonad e Roberto Luís de Melo Monte-Mór.

17 Designação do encontro conjunto promovido pela Association of European Schools of Planning (AESOP) e a Association of Collegiate Schools of Planning (ACSP). 
no formato da revista e contribuíram para reduzir significativamente o peso da revista no orçamento da associação. Por outra parte, a renovação da Comissão Editorial e de parte do Conselho Editorial contemplando a diversidade disciplinar e a distribuição regional dos membros da associação contribuiu sobremaneira para uma interação mais orgânica da associaçáo com seus membros, em termos de pertencimento, bem como para conferir uma maior representatividade destes no corpo da revista.

Nesse sentido cabe um agradecimento dessa gestão, em especial, a Carlos Antônio Brandão e a Fernanda Sánchez, que assumiram a editoria da revista no segundo semestre de 2012, bem como cabe uma agradecimento aos demais membros da Comissão Editorial, pois graças aos seus esforços, conseguiu-se, enfim, colocar a revista em dia e em condiçôes de ser submetida aos principais indexadores exigidos pelos órgãos de fomento, entre eles o SciELO, havendo obtido a inserção da revista no diretório do Sistema Regional de Información en Línea para Revistas Científicas de América Latina, el Caribe, Espańa y Portugal (Latindex), no portal de periódicos da CAPES, no Sistema de Editoração Eletrônica de Revistas (SEER) do Instituto Brasileiro de Informação em Ciência e Tecnologia (IBICT), e sua aprovação no CrossRef, o que garante a todas as publicaçóes online da ANPUR um Digital Object Identifier (DOI). Este conjunto de conquistas deu condiçóes à que a equipe renovada da Revista olhasse para a frente, para o futuro e contribuiu para aumentar a visibilidade da associação e da produçáo de seus membros.

A estas realizaçôes da revista veio se somar a criação de um portal de publicaçôes com acesso livre aos anais de todos os eventos da ANPUR dos últimos trinta anos unificado com a revista em uma única base de busca no formato OJS, preservando, todavia, as identidades de cada publicaçâo com a possibilidade de cada um contar com um identificador digital (DOI). Isto permite um link direto das publicaçôes da ANPUR contidas nos curriculum lattes de cada autor com as suas publicaçóes dos últimos trinta anos disponibilizadas online.

Este portal da ANPUR deve contribuir para aumentar ainda mais a visibilidade da associação, para difundir a produçáo contida em nossas publicaçôes e para afirmar a ANPUR como um importante órgão de pesquisa e ensino no campo dos estudos urbanos e regionais.

Soma-se a estes esforços a publicação da coleção de livros da Gestão 2011-2013, que conta com os três livros das mesas redondas do XIV Encontro Nacional da ANPUR ${ }^{18}$, o livro homenagem a Ana Clara Torres Ribeiro" ${ }^{19}$ o livro organizado sob a chancela ANPUR-SBPC: "Um novo planejamento para um novo Brasil?" ${ }^{20}$, quase todos disponibilizados no formato e-book. Aos quais se somam a tese $e^{21}$ e a dissertação ${ }^{22}$ premiadas durante o XIV Encontro Nacional da ANPUR.

Enfim, como um meio de ampliar a representatividade e interlocução da ANPUR com seus membros durante essa gestão foi realizado o I Seminário de Desenvolvimento Regional, Estado e Sociedade, organizado pelo IPPUR-UFRJ, sob a coordenação do professor Rainer Randolph, que veio a se somar ao conjunto de seminários itinerantes da associação.

\section{PERSPECTIVAS FUTURAS}

Enfim, após trinta anos, podemos dizer que a ANPUR encontra-se consolidada e madura institucionalmente. A associação conta hoje com sessenta e cinco membros, $33 \%$ dos quais na área de planejamento urbano e regional. A área de Planejamento Urbano e Regional se consolidou e ganhou força política e acadêmica na CAPES e no CNPq, apresentando nos últimos anos uma crescente demanda por fomento relacionado à formação e à pesquisa.

18 Ribeiro, Egler e Sánchez (2012); Ribeiro, Limonad e Gusmão (2012); e Ribeiro, Vaz e Silva (2012).

19 Ribeiro (2012).

20 Limonad e Castro (2014).

21 Cota (2013).

22 Souza (2013). 
A participação efetiva da ANPUR nas Conferências Nacionais e Estaduais do Desenvolvimento e a construção de uma política nacional de desenvolvimento regional, mostram claramente a importância da ANPUR, única associação científica com assento na comissão executiva do Ministério da Integração Nacional. Todavia, esta participação é limitada, uma vez que esta comissão é recortada por interesses diversos, com possibilidades limitadas de intervenção. Da mesma forma, a participação efetiva da ANPUR nas Conferências Nacionais e Estaduais das Cidades e a construção de uma política nacional de desenvolvimento urbano demonstram a relevância e contribuição da ANPUR, e os limites e desafios desta participação. Neste sentido coloca-se para as gestôes futuras a necessidade de refletir acerca das formas de participação institucional da associação e na possibilidade de constituição de câmaras técnicas de intervenção e de resposta ou de seçóes regionais da associação.

Resta muito que fazer. Mais do que nunca é necessário reforçar a visibilidade da associação através de seus principais veículos de difusão como os anais e a revista. Intensificar as relaçôes com nossos parceiros, com outras associaçôes nacionais de pós-graduação e com a SBPC no sentido de aumentar o intercâmbio interdisciplinar e buscar articulaçôes frente as propostas que se colocam para o futuro, principalmente no âmbito do CNPq, que nos apresentou um programa que privilegia a interrelação Universidade-Empresa, em que apenas $5 \%$ da verba será direcionada para as áreas de pesquisa.

Em termos do fomento, urge uma articulação da ANPUR com as outras associaçóes de áreas afins para reivindicarmos conjuntamente por uma diretoria de ciências humanas e sociais aplicadas no CNPq, pois o Programa Ciências sem Fronteiras tem fronteiras. E as áreas de Ciências Sociais Aplicadas e de Ciências Humanas encontram-se subordinadas à área de Engenharias. Havendo já uma articulação no âmbito da SBPC, que como se apontou apenas começa a se esboçar.

Há que se pensar no papel dos programas-membro na formação de profissionais, o que compreende também pensar na formação de cursos de graduação em planejamento, como começam a surgir em outros países com realidades muito semelhantes a nossa em diferentes graus como a Índia, Turquia e no outro extremo o Canadá.

Cabe dentro da perspectiva futura intensificar as relaçôes exteriores, aumentar nosso peso no GPEAN e com outras associaçóes internacionais. O Seminário de Experiências Internacionais de Planejamento ${ }^{23}$ realizado durante o XV ENANPUR mostrou que partilhamos diversos problemas, experiências e questóes comuns.

Cabe considerar a interação universidade-sociedade e o papel da ANPUR nessa interação, bem como as possibilidades de sua contribuição crítica na emancipação de diferentes grupos sociais e em processos de emancipação e transformação social, com um compromisso de construção nacional.

Durante esta gestão muito foi feito e, sem dúvida, gostaríamos de haver feito mais ainda. A lista de agradecimentos é infindável, a começar por todos aqueles que se dispuseram a dividir o trabalho e as afliçôes, passando por todos que assumiram um compromisso institucional com esta diretoria; bem como por todos aqueles que contribuíram com sugestôes e observaçóes, sem deixar de lado, também, as contribuiçôes mais críticas.

Cabe agradecer a todos os que nos precederam, por seu legado e por seu empenho na construção da ANPUR, tarefa infindável, pois as exigências legais e institucionais só fazem aumentar, sendo que cada vez aparece uma novidade e mais uma exigência burocrática. Porém, graças ao apoio efetivo e à ajuda das gestóes precedentes, conseguimos avançar para colocar a associação em dia com todas as exigências legais, ou seja, não restam pendências.

Enfim, cabe um agradecimento especial aos meus companheiros de diretoria, que dividiram comigo a responsabilidade de conduzir essa gestão, Benny Schvarsberg e Orlando dos Santos Júnior, bem como aos demais membros que direta ou indiretamente contribuíram para isso como Cibele Saliba

23 Que contou com a participação de Andrea Frank (University of Cardiff - United Kingdom), Bruce Stiftel (Georgia Tech - United States of America), David Amborski (Ryerson University - Canada) e Nancy Odendaal (University of Cape Town - South Africa). 
Rizek, Maria Ângela de Almeida Souza, María Mónica Arroyo, Saint-Clair Trindade Júnior, Elson Manoel Pereira por dividirem o trabalho, por seu apoio, por sua confiança e por terem assumido esta jornada de levarmos juntos a bom termo a gestáo de Ana Clara Torres Ribeiro.

E, encerro essa memória com algumas palavras de Ana Clara Torres Ribeiro, que inspiraram essa gestão e que ficam como uma mensagem para o futuro:

Porque para $[. .$.$] configurar a esfera de poder, que controla a sua liberdade, controla a minha, controla a sua$ existência, cria os tributos, absolve a sua vida, resolve as vagas da universidade, resolve tudo isto, pra você ter o direito a isto é necessário que você tenha a responsabilidade por esse direito que você exerce em direção a alguma coisa que seja maior do que você.

Porque se não for isso é pura perversão. É pura perversidade no exercício do poder. E isso é o que o governante normalmente é. Ele é incapaz de ultrapassar essa face perversa do exercício do poder para ter grandeza. E, como um homem renascentista, no caso Machiavel, é um exercício da virtù, a virtude. Então, a virtude, no sentido de que está pra além da coisa do homem público, que está para além do privado, está para além do familiar, está para além do familismo, está para além dos meus amigos, está para além disso tudo, na medida em que existe alguma coisa que é o público, que é a virtù, que é a honra individual transformada pela modernidade, mas que caminha pra algo maior. Nesse sentido, o exercício do poder está para além da coisa banal, simplesmente da herança de um poder (RIBEIRO, 2014).

\section{REFERÊNCIAS}

ASSOCIAÇÃO NACIONAL DE PÓS-GRADUAÇÃO E PESQUISA EM PLANEJAMENTO URBANO E REGIONAL - ANPUR. Anais do I Encontro Nacional da ANPUR. Rio de Janeiro: ANPUR/ CNPq/ FINEP/ CNDU/ BNH, 1986. Ata da Assembleia Geral Ordinária. Águas de Sáo Pedro: ANPUR, 1989. Ata da Assembleia Geral Extraordinária de 29.05.2009. Florianópolis: ANPUR, 2009. Ata da Assembleia Geral Ordinária de 27.05.2011. Rio de Janeiro: ANPUR, 2011. Ata da Assembleia Geral Ordinária de 02.04.2012. Rio de Janeiro: ANPUR, 2012a. Ata da Assembleia Geral Extraordinária de 08.11.2012. Brasília: ANPUR, 2012b. Ata da Assembleia Geral Ordinária de 08.11.2012. Brasília: ANPUR, 2012c. Ata da Assembleia Geral Ordinária de 24.05.2013. Recife: ANPUR, 2013.

COTA, D. A. A parceria público-privado na política urbana brasileira recente. Rio de Janeiro: Letra Capital, ANPUR, 2013.

FERNANDES, A. Tendências e Desafios no Fomento à Pesquisa na área do Planejamento Urbano e Regional: uma análise a partir do CNPq. Revista Brasileira de Estudos Urbanos e Regionais, v. 15, n. 1, p. 59-76, maio 2013. https://doi.org/10.22296/2317-1529.2013v15n1p59

LIMONAD, E.; CASTRO, E. R. (Org.). Um novo Planejamento para um novo Brasil. Rio de Janeiro: Letra Capital, ANPUR, 2014.

RANDOLPH, R. Em busca de uma agenda para o Planejamento Urbano e Regional: uma homenagem a Ana Clara Torres Ribeiro. Revista Brasileira de Estudos Urbanos e Regionais, v. 15, n. 1, p. 11-31, maio 2013. https://doi.org/10.22296/2317-1529.2013v15n1p11

; LIMONAD, E. Balanço da produção técnico-científica em Planejamento Urbano, Regional e Tecnologia Habitacional. Rio de Janeiro: ANPUR/ CNPq/ FINEP/ CNDU/ BNH, 1986 (mimeo).

RIBEIRO, A. C. T. Por uma Sociologia do Presente. Rio de Janeiro: Letra Capital, ANPUR, 2012.

Por uma Sociologia do Presente. Rio de Janeiro: Letra Capital, 2013. 5 v. (Org.). Teorias da Ação. Rio de Janeiro: Letra Capital, 2014.

; EGLER, T. T. C.; SÁNCHEZ, F. (Org.). Politica governamental e ação social. Rio de Janeiro: Letra Capital, ANPUR, 2012. 
; LIMONAD, E.; GUSMÃO, P. P. (Org.). Desafios ao Planejamento. Rio de Janeiro: Letra Capital, ANPUR, 2012.

; VAZ, L. F.; SILVA, M. L. P. (Org.). Leituras da Cidade. Rio de Janeiro: Letra Capital, ANPUR, 2012.

ROVATI, J. Urbanismo versus Planejamento Urbano e Regional? Revista Brasileira de Estudos Urbanos e Regionais, v. 15, n. 1, p. 33-58, maio 2013. https://doi.org/10.22296/2317-1529.2013v15n1p33

SOUZA, M. F. S. A Festa e a Cidade. Rio de Janeiro: Letra Capital, ANPUR, 2013.

Ester Limonad é graduada em Arquitetura e Urbanismo pela Universidade Presbiteriana Mackenzie (UPM); mestra em Planejamento Urbano e Regional pela Universidade Federal do Rio de Janeiro (UFRJ); doutora em Arquitetura e Urbanismo pela Universidade de São Paulo (USP); professora titular no Departamento de Geografia da Universidade Federal Fluminense (UFF); Bolsista de Produtividade do CNPq; presidente da ANPUR entre 2011 e 2013.

E-mail:ester_limonad@yahoo.com 